\title{
Prevalence of Type of Removable Dentures in Elderly Citizens in the Northern India
}

\author{
${ }^{1}$ Sushil Kar, ${ }^{2}$ Arvind Tripathi
}

\begin{abstract}
Aims and objectives: The aim of this study was to evaluate the prevalence of removable partial dentures (RPD), conventional complete dentures (CCD) in elderly citizens in Northern India and to identify factors that might be associated with the findings.
\end{abstract}

Materials and methods: The survey was carried out in the nearby villages under the aegis of Saraswati Dental College, Lucknow, Uttar Pradesh, India $(n=1,050)$ from the period March 2013 to March 2014. The age range of the subjects was 55 to 70 years. In addition to a clinical examination, data on background factors were obtained using questionnaires and/or interviews.

Results: Overall, $12.4 \%$ of men and $12.1 \%$ of women had RPD, while $8 \%$ of men and $4.8 \%$ of women had CCD. Among the dentate subjects, $18.8 \%$ have posterior RPDs and $9.9 \%$ have anterior RPDs.

Conclusion: A logistic regression analysis showed that the prevalence of dentures in the form of removable dentures and complete dentures were relatively low in elderly citizens in the northern India.

Keywords: Edentulism, Overdentures, Satisfaction.

How to cite this article: Kar S, Tripathi A. Prevalence of Type of Removable Dentures in Elderly Citizens in the Northern India. J Contemp Dent 2015;5(2):76-79.

Source of support: Nil

Conflict of interest: None

\section{INTRODUCTION}

The main objective of a prosthetic rehabilitation is to provide function, esthetic and oral health to the patients, especially to those who have experienced complete tooth loss or having few remaining teeth. ${ }^{1}$ Because various treatment options to replace missing teeth exist, the choice of prosthodontic treatment needs to take the multidimensional nature of health and the treatment's outcomes into consideration. Although implant therapy has proved to be a successful solution for missing teeth, conventional removable and complete dentures

\footnotetext{
${ }^{1}$ Professor, ${ }^{2}$ Professor and Head

1,2Department of Prosthodontics, Saraswati Dental College Lucknow, Uttar Pradesh, India

Corresponding Author: Sushil Kar, Professor, Department of Prosthodontics, Saraswati Dental College, Lucknow Uttar Pradesh, India, Phone: 0522423879, e-mail: drsushil_ kar@yahoo.co.in
}

remain the only treatment option for the great majority of patients in India, especially because of economical limitations. ${ }^{1,2}$

The epidemiology of oral rehabilitation using removable prosthodontics has not been extensively investigated. Only a few studies have examined the frequency of prosthetic treatments performed at the population level, i.e. how many units of different types of prosthetic appliances have been fabricated within a distinct period or for a certain population. ${ }^{3}$ Additionally, few epidemiological studies have been undertaken on the provision of removable prosthodontics performed for the Indian population. Previous denture quality assessment of 1,306 removable partial dentures (RPDs) in the United States found that $65 \%$ of the RPDs had various types of defects, ${ }^{4}$ indicating potential for quality improvement. Combined with the high prevalence of RPDs in the general Indian population, improvement of RPD quality could have a substantial effect on population oral health.

Partial edentulism with or without wearing of RPD has been the subject of many studies and the patient acceptance of a reduced dentition as well as the satisfaction with RPDs is documented for different groups. ${ }^{5,6}$ It would from the results of these studies be reasonable to expect RPD wearers to be dissatisfied with their oral conditions. On the other hand, the motivation for RPD use may be of a social meaning to such an extent that they are considered as an important body part. ${ }^{78}$ In India, it has been shown that although the prevalence of crowns has increased over the years in all social groups, patients with lower socioeconomic group tend to have more removable dentures than those with higher socioeconomic group. The level of education may reflect the patients' attitudes to dental care, including their acceptance of dental care and their preference for treatment modalities ${ }^{9}$ (preventive and restorative treatment).

Access to prosthodontic treatment is much related to the funding systems. Because of lack of motivation and financial constraint, most of the rural Indian population who wants teeth replacement, visit to a local non-qualified street dentist. The street dentist fixes the prefabricated interim RPD to the adjacent teeth by the help of self cure acrylic resin. This form of prosthesis within a span of month create tremendous periodontal 
breakdown of the adjacent teeth which end up with the mobility and removable of the prosthesis.

The aim of the study was to evaluate the prevalence of RPD, conventional complete dentures (CCD) in elderly citizens in northern India during March 2013 to March 2014. The second aim was to evaluate the factors associated with the prevalence of removable prostheses in these subjects.

\section{MATERIALS AND METHODS}

This cross-sectional, descriptive epidemiological survey was carried out in the nearby villages under the aegis of Saraswati Dental College, Lucknow, Uttar Pradesh, India ( $n=1,050$ ) over a period of 1 year. The final sample consisted of 1,050 subjects. The age range of the subjects was 55 to 70 years. Data on background factors (age, gender, level of education, healthcare utilization, including dental care) were obtained using questionnaires and/or interviews in conjunction with a clinical examination. ${ }^{14}$ Out of 1,050 subjects, 497 subjects were women and 553 subjects were men (Tables 1 and 2). The dentate subjects were numbered 687 in total.

The presence of RPD, CCD were evaluated from the normal oral examination. The evaluation was performed by faculty staffs specialized in prosthetic dentistry. The prevalence of implant supported overdentures (ISOD) was so low that no further analyses were carried out on that treatment option. Conventional complete dentures and conventional overdentures (COD) were categorized as one entity, because of less number of COD reported during the defined period.

Bivariate associations between the presence of removable partial dentures and complete dentures and potentialrelated factors were evaluated using a Chi-square test. The factors were age, gender, education (middle/primary level/vocational or less), number of visits to a dentist (once in 2 years or less/more than once in 2 years) and place of residence. Logistic regression analysis was used as a multivariate model to assess the associations. The relationship between the presence of removable partial dentures and complete dentures and background factors was assessed by odds ratios (OR) with 95\% confidence intervals (95\% CI).

\section{RESULTS}

In the whole sample, the prevalence of CCDs was higher among men than among women (Table 1), and in the dentate sample, men showed higher prevalence of removable partial dentures than women (Table 1). Within dentate subjects, the difference of prevalence between posterior and anterior RPDs was emphasized (Table 1). Five men $(1.7 \%)$ and five women (1.7\%) had RPD being fixed with the adjacent teeth and $1.1 \%$ of men and women had conventional overdentures .

In the multivariate analysis, the presence of removable partial dentures and complete dentures was significantly associated with subjects above poverty line (OR 3.9, 95\% CI 2.4-6.4), a medium (OR 5.6, 95\% CI 3.3-9.4) or a low level of education (OR 3.2, 95\% CI 2.0-5.0). The association between age and gender with the prevalence of crowns or fixed partial dentures (FPDs) disappeared in the multivariate analyses (Tables 2 and 3).

\section{DISCUSSION}

The present study found that in the study conducted between March 2013 to March 2014 among the elderly in the villages of Northern India, $12.3 \%$ had some form of RPDs and $6.5 \%$ had CCDs. The numbers of conventional overdentures and cast partial dentures were minimal. The prevalence of RPDs was six times higher and the prevalence CCDs was almost three times higher in above the poverty line population. The prevalence is lower although the villages are located quite near to the districts and the towns. The regional differences found in the present study may be related to a lower level of education and socioeconomic status in the villages and to difference in attitudes towards dental care. In earlier years, the number of dentists has been lower in the nearby districts although in recent years the situation has become balanced.

In the present study, the prevalence of complete dentures was evaluated which included both conventional complete dentures and overdentures even though the prevalence of later was very minimal. It should be noted that the treatment modalities are based on separate indications. The prevalence of overdentures was very low, constituting only 0.3 to $0.4 \%$ of the total sample and among the higher socioeconomic group.

Table 1: Prevalence of removable partial dentures and complete dentures in 55 to 70 -year-old subjects in the villages of Northern India

\begin{tabular}{|c|c|c|c|c|c|c|}
\hline & \multicolumn{2}{|c|}{ All men } & \multicolumn{2}{|c|}{ All women } & \multicolumn{2}{|c|}{ Total } \\
\hline & $\bar{n}$ & $\%$ & $\bar{n}$ & $\%$ & $\bar{n}$ & $\%$ \\
\hline Total subjects & 553 & 53 & 497 & 47 & 1050 & 100 \\
\hline RPD & 67 & 12.1 & 62 & 12.24 & 129 & 12.23 \\
\hline CCD & 44 & 8 & 24 & 4.8 & 68 & 6.5 \\
\hline Dentate subjects & 324 & 47 & 363 & 53 & 687 & 65 \\
\hline Posterior RPD & 56 & 26.5 & 56 & 22.9 & 112 & 24.6 \\
\hline Anterior RPD & 11 & 9.7 & 6 & 5.0 & 17 & 4.4 \\
\hline
\end{tabular}


Table 2: Multivariate analysis of the presence of removable partial dentures and complete dentures and explanatory factors in 55 to 70 -year-old subjects in the villages of Northern India

\begin{tabular}{|c|c|c|}
\hline Explanatory variables & $\begin{array}{l}\text { OR }(95 \% \mathrm{Cl}) n= \\
1013 \text { (edentulous }= \\
358, \text { dentate }=655)\end{array}$ & $\begin{array}{l}p \text {-value tested } \\
\text { by Chi-square } \\
\text { test }\end{array}$ \\
\hline Age & $0.977(0.946 ; 1.009)$ & 0.359 \\
\hline Gender, male vs female & $1.043(0.737 ; 1.476)$ & 0.810 \\
\hline $\begin{array}{l}\text { Above poverty line vs } \\
\text { below poverty line }\end{array}$ & $6.162(3.813 ; 9.957)$ & 0.000 \\
\hline $\begin{array}{l}\text { Education, middle level } \\
\text { vs primary or less }\end{array}$ & $9.479(5.735 ; 15.667)$ & 0.000 \\
\hline $\begin{array}{l}\text { Education, low level vs } \\
\text { vocational or less }\end{array}$ & $4.166(2.693 ; 6.444)$ & 0.000 \\
\hline
\end{tabular}

Table 3: Multivariate analysis of the presence of removable partial dentures and explanatory factors in 55 to 70 -year-old dentate subjects in the villages of Northern India

\begin{tabular}{|c|c|c|}
\hline Explanatory variables & OR $(95 \%$ Cl) $n=655$ & $\begin{array}{l}p \text {-value tested by } \\
\text { Chi-square test }\end{array}$ \\
\hline Age & $1.021(0.987 ; 1.057)$ & 0.265 \\
\hline $\begin{array}{l}\text { Gender, male vs } \\
\text { female }\end{array}$ & $1.360(0.944 ; 1.959)$ & 0.098 \\
\hline $\begin{array}{l}\text { Above poverty line vs } \\
\text { below poverty line }\end{array}$ & $3.907(2.382 ; 6.406)$ & 0.000 \\
\hline $\begin{array}{l}\text { Education, middle level } \\
\text { vs primary or less }\end{array}$ & 5.625 (3.353; 9.438) & 0.000 \\
\hline $\begin{array}{l}\text { Education, low level vs } \\
\text { vocational or less }\end{array}$ & $3.200(2.034 ; 5.034)$ & 0.000 \\
\hline
\end{tabular}

Although the prevalence levels of complete dentures were found to be higher among men in the present study, the association with gender was not confirmed in the multivariate analysis. In the present sample, the prevalence of edentulousness has shown to be higher among men than in women and this may affect the association. Among dentate, male gender showed higher association with the prevalence of anterior and posterior RPDs than in the whole sample. The reason for the low prevalence rate among women might be due to the low education and cultural background which restricts them to undergo dental treatment.

No correlation was found between the age of the subject and the prevalence of removable partial dentures and complete dentures in the present study. The age of the patient has been shown to be a factor in complications related to complete dentures with significantly more complications in patients over 65 years than in younger patients. ${ }^{10}$ However, cut-off points in patient age for surviving dentures could not be found and removable partial dentures can still be recommended as durable dental replacement for elderly patients. ${ }^{11}$

Despite the advanced age of dentures, the functional assessment scores were generally high. This result could be attributed to the fact that dentists assess dentures using predetermined criteria for success based on technical standards which usually do not take into account the individual needs and attitudes of patients ${ }^{12,13}$ or their previously expectations about dentures. The problems observed on these dentures were small denture base fractures, presence of biofilm, stains, deterioration of denture base resin, which did not necessarily reflect on functional problems. ${ }^{14,15}$ These conditions were not considered on examiner's judgment of dentures as they do not have influence on the prevalence rate evaluated in this study.

The strength of the present study is the relatively high participation rate, $62 \%$ among above poverty line and $78 \%$ among below poverty line. This sample represents well the elderly population in the villages of Northern India. All the clinical examinations were carried out based on one format, which excludes the risk of inter examination errors. To update the prevalence levels in recent years also in other villages of India, further studies are needed.

\section{CONCLUSION}

It can be concluded that the prevalence of removable partial dentures and complete dentures was relative low in elderly citizens in the villages of Northern India in the recent period. The present study showed that socioeconomical factors and utilization of dental healthcare were associated with the prevalence of removable partial dentures and complete dentures. Overall, $12.4 \%$ of men and $12.1 \%$ of women had single crowns, while $4.8 \%$ of RPD and $8.0 \%$ of men had complete dentures. Regional and cultural inequality (villages and city of northern India) in the provision quality dental treatment for the elderly was observed.

\section{ACKNOWLEDGMENTS}

The work was supported by the management of the Institution with full cooperation. The participation of responding postgraduate students and patients is acknowledged.

\section{REFERENCES}

1. Mericske-Stern R. Removable partial dentures. Int J Prosthodont 2009;22(5):508-511.

2. Wöstmann B, Budtz-Jørgensen E, Jepson N, et al. Indications for removable partial dentures: a literature review. Int J Prosthodont 2005;18(2):139-145.

3. Liedberg B, Stoltze K, Ö wall B. The masticatory handicap of wearing removable dentures in elderly men. Gerodontology 2005;22(1):10-16.

4. Szentpétery AG, John MT, Slade GD, Setz JM. Problems reported by patients before and after prosthodontic treatment. Int J Prosthodont 2005;18(2):124-131.

5. Armellini DB, Heydecke G, Witter DJ, Creugers NH. Effect of removable partial dentures on oral health-related quality of life in subjects with shortened dental arches: a two-center cross-sectional study. Int J Prosthodont 2008;21(6):524-530. 
6. Carlsson GE, Hedegård B, Koivumaa KK. Late results of treatment with partial dentures. An investigation by questionnaire and clinical examination 13 years after treatment. J Oral Rehabil 1976;3(3):267-272.

7. Koyama S, Sasaki K, Yokoyama M, Sasaki T, Hanawa S. Evaluation of factors affecting the continuing use and patient satisfaction with removable partial dentures over 5 years. J Prosthodont Res 2010;54(2):97-101.

8. Zlatarić DK, Celebić A. Factors related to patients' general satisfaction with removable partial dentures: a stepwise multiple regression analysis. Int J Prosthodont 2008;21(1):86-88.

9. Akeel RF. Effect of the quality of removable prostheses on patient satisfaction. J Contemp Dent Pract 2009;10(6):E057E064.

10. Jacob RF. The traditional therapeutic paradigm: complete denture therapy. J Prosthet Dent 1998;79(1):6-13.
11. Pietrokovski J, Harfin J, Mostavoy R, Levy F. Oral findings in elderly nursing home residents in selected countries: quality of and satisfaction with complete dentures. J Prosthet Dent 1995;73(2):132-135.

12. Sato $Y$, Hamada S, Akagawa $Y$, Tsuga K. A method for quantifying overall satisfaction of complete denture patients. J Oral Rehabil 2000;27(11):952-957.

13. De Souza e Silva ME, de Magalhaes CS, Ferreira E. Complete removable prostheses: from expectation to dissatisfaction. Gerodontology 2009;26(2):143-149.

14. Corrigan PJ, Basker RM, Farrin AJ, Mulley GP, Heath MR. The development of a method for functional assessment of dentures. Gerodontology 2002;19(1):41-45.

15. Fenlon MR, Sherriff M. Investigation of new complete denture quality and patients' satisfaction with and use of dentures after two years. J Dent 2004;32(4):327-333. 